\title{
The mechanism of long-term low-dose asymmetric dimethylarginine inducing transforming growth factor- $\beta$ expression in endothelial cells
}

\author{
YIDUO FENG, DONGLIANG ZHANG, YU ZHANG, QIDONG ZHANG and WENHU LIU \\ Department of Nephrology, Affiliated Beijing Friendship Hospital, Faculty of Kidney Diseases, \\ Capital Medical University, Xi Cheng, Beijing 100050, P.R. China
}

Received July 30, 2012; Accepted September 24, 2012

DOI: 10.3892/ijmm.2012.1190

\begin{abstract}
Asymmetric dimethylarginine (ADMA), an endogenous nitric oxide synthase (NOS) inhibitor, accumulates in plasma during chronic kidney disease (CKD). High plasma levels of ADMA can increase transforming growth factor- $\beta$ (TGF- $\beta$ ) expression, related to renal fibrosis, but the precise molecular mechanism is not explicit. The present study was designed to determine the mechanism through which long-term low-dose ADMA induces TGF- $\beta$ expression in endothelial cells and to investigate the molecular mechanism of its action. Human umbilical vein endothelial cells (HUVECs) were exposed to low-dose ADMA (5 and $10 \mu \mathrm{mol} / \mathrm{l}$ ) for 7 passages and TGF- $\beta$ expression was determined. Human renal glomerular endothelial cells (HRGECs) were exposed to high-dose ADMA $(100 \mu \mathrm{mol} / \mathrm{l})$ which were used to clarify the molecular mechanism. The results showed that long-term low-dose ADMA (5 and $10 \mu \mathrm{mol} / \mathrm{l}$ ) increases TGF- $\beta$ production in both mRNA and protein levels in HUVECs in a time-dependent manner. We confirmed that exogenous ADMA $(100 \mu \mathrm{mol} / \mathrm{l})$ significantly enhanced stress fiber formation in HRGECs and upregulated TGF- $\beta$ expression. Such effects of ADMA in HRGECs were inhibited by pre-treatment with actin depolymerizing agent, actin stabilizing agent, p38 MAPK inhibitor and NADPH oxidase inhibitor. In addition, we demonstrated that ADMA $(100 \mu \mathrm{mol} / \mathrm{l})$ significantly activated nuclear factor- $\mathrm{kB}(\mathrm{NF}-\mathrm{\kappa B})$ in HRGECs, which was markedly attenuated by actin depolymerizing agent, actin stabilizing agent, p38 MAPK inhibitor and NADPH oxidase inhibitor. In brief, the present study demonstrated that long-term low-dose ADMA induces TGF- $\beta$ expression in endothelial cells at both the gene
\end{abstract}

Correspondence to: Professor Wenhu Liu, Department of Nephrology, Affiliated Beijing Friendship Hospital, Faculty of Kidney Diseases, Capital Medical University, 95 Yong An Road, Xi Cheng District, Beijing 100050, P.R. China

E-mail: liuwh2002@yahoo.cn

Key words: asymmetric dimethylarginine, endothelial cell, transforming growth factor- $\beta$, cytoskeleton, nuclear factor- $\kappa \mathrm{B}$ and protein levels. The actin cytoskeleton may be involved in modulation of ADMA-induced NF- $\kappa \mathrm{B}$ activation and the ensuing TGF- $\beta$ expression in HRGECs.

\section{Introduction}

Nitric oxide (NO) is synthesized by stereospecific oxidation of terminal guanidine nitrogen of L-arginine by the action of the NO synthase (NOS) (1). The synthesis of NO can be blocked by inhibition of the NOS active site with guanidine-substituted analogues of L-arginine, such as asymmetric dimethylarginine (ADMA) $(2,3)$, which is an important risk factor for endothelial dysfunction.

Numerous studies have revealed that a high level of ADMA is associated with increased renal oxidative stress (ROS) $(4,5)$ and activated the oxidant-responsive transcription factor nuclear factor- $\kappa \mathrm{B}(\mathrm{NF}-\kappa \mathrm{B})$, which enhanced cytokine expression in human endothelial cells (6). Furthermore, in hepatic stellate cells, treatment with ADMA significantly increased the intracellular ROS production and activated $\mathrm{NF}-\kappa \mathrm{B}$. The effects of ADMA on the level of transforming growth factor- $\beta$ (TGF- $\beta$ ) mRNA could be markedly attenuated by pre-treatment with antioxidant pyrrolidine dithiocarbamate (7). We, and others, have demonstrated that actin cytoskeleton modulates ADMA-induced NF- $\mathrm{B}$ nuclear translocation in previous studies, which plays a critical role on endothelial cell dysfunction $(8,9)$. ADMA can also increase endothelial permeability, which may involve the p38 MAPK and NADPH signal pathway (10).

ADMA is considered an independent mortality and cardiovascular risk factor in chronic kidney disease (CKD) patients (11-13). Matsumoto et al (14) indicated that high plasma levels of ADMA are associated with decreased number of peritubular capillaries, increased tubulointerstitial fibrosis, TGF- $\beta$ expression and proteinuria levels in five-sixths subtotal nephrectomy (Nx) rats. These data and similar observations of other authors suggest that ADMA may contribute to the progression of CKD (14-16). Furthermore, ADMA exposure induced glomerular and vascular fibrosis as evidenced by the elevated deposits of collagens I, III and fibronectin, suggesting that in pathophysiological conditions of endothelial dysfunction, the exaggerated endogenous synthesis of ADMA could contribute to CKD 
progression by extracellular matrix synthesis (17). It was accepted that TGF- $\beta$ was related to renal fibrosis. However, the precise molecular mechanisms underlying ADMA-induced TGF- $\beta$ expression is not explicit.

In addition, the current experimental research uses, primarily, high concentration (10-500 $\mu \mathrm{mol} / \mathrm{l})$ and short-term (12-24 h) incubation conditions to study the cellular effects of ADMA. However, the level is lower (1-10 $\mu \mathrm{mol} / \mathrm{l})$ and the affliction proceed during the whole period in the high blood level ADMA diseases, such as CKD, cardiovascular disease (CVD), hypertension, and diabetes. The present study was designed to determine the effects of long-term low-dose ADMA on the TGF- $\beta$ expression in endothelial cells and to investigate the underlying molecular mechanisms.

\section{Materials and methods}

Cell culture. Primary human renal glomerular endothelial cells (HRGECs) and primary human umbilical vein endothelial cells (HUVECs) were purchased from ScienCell Research Laboratories (San Diego, CA, USA). Both were cultured in endothelial cell medium (ECM) (ScienCell Research Laboratories) containing 5\% fetal bovine serum (FBS), $1 \%$ endothelial cell growth supplement (ECGS) and $1 \%$ penicillin/streptomycin solution (P/S).

The medium of HRGECs was changed every two days. Actively growing HRGECs at the third to the fifth passage were used for experiments.

HUVECs were used in the long-term low-dose ADMA stimulation. ADMA was replaced every $48 \mathrm{~h}$ starting at the fourth passage until the ninth passage. After reaching confluence (between 8-9 days), endothelial cells were trypsinized and seeded at a density of 2,500 cells $/ \mathrm{cm}^{2}$ per $25 \mathrm{~cm}^{2}$ flasks. Following detachment with trypsin telomerase activity, mRNA and protein levels of TGF- $\beta$ expression were analyzed.

Western blot analysis. Cells were lysed with RIPA lysis buffer. Protein concentrations were determined using a BCA assay, soluble proteins were separated on $12 \%$ SDS-polyacrylamide gels and transferred to polyvinylidene difluoride membranes. Nonspecific membrane binding was blocked for $1 \mathrm{~h}$ at room temperature with 5\% BSA (or milk) in phosphate-buffered saline containing $0.05 \%$ Tween-20. Membranes were incubated overnight at $4^{\circ} \mathrm{C}$ with primary antibodies (1:50; Beijing Zhongshan Golden Bridge Biotechnology Co., Ltd., Beijing, China). After washing, membranes were incubated with horseradish peroxidase-conjugated secondary antibodies for $1-2 \mathrm{~h}$ at room temperature in blocking buffer. Signals generated by the chemiluminescent substrate were captured by ECL plus reagent (Sun Bio Corp., Beijing, China), and the images were analyzed by densitometry using Labworks Image Acquisition and Analysis Software (Ultra-Violet Products, Ltd., Cambridge, UK). Protein bands were quantified by densitometry using the analysis software Image.

Quantitative real-time PCR. Total-RNA was isolated from cells using the TRIzol reagent (Invitrogen, USA) and was quantified by analysis of absorbance at $260 \mathrm{~nm}$. Relative gene expression levels were calculated using the comparative threshold-cycle method of quantitative PCR, with data normalized to GAPDH and expressed relative to untreated controls. Real-time PCR was performed using the BioEasy SYBR-Green I Real-Time PCR kit (Bioer Technology Co., Ltd, China), according to the manufacturer's instructions. The primers used to amplify TGF- $\beta$ were: 5'-GCCAGAGTGGTTATCTTTTGATG-3' and 5'-AGTGTGTTATCCCTGCTGTCAC-3'. The total volume used in PCR was $20 \mu \mathrm{l}$. All experiments were performed in triplicate.

Electrophoretic mobility shift assay (EMSA). Ten micrograms of nuclear extract were incubated with $1 \mu \mathrm{g}$ of poly $(\mathrm{dI}-\mathrm{dC})$ in a binding buffer (10 mM Tris- $\mathrm{HCl}, \mathrm{pH} 7.5,50 \mathrm{mM} \mathrm{NaCl}, 0.5 \mathrm{mM}$ dithiothreitol, $10 \%$ glycerol, $20 \mu \mathrm{l}$ final volume) for $15 \mathrm{~min}$ at room temperature. Then, end-labeled double-stranded oligonucleotides containing an NF- $\mathrm{BB}$ site $(30,000 \mathrm{cpm}$ each) were added and the reaction mixtures were incubated for $15 \mathrm{~min}$ at room temperature. The DNA-protein complexes were resolved in 5\% native polyacrylamide gel electrophoresis in low ionic strength buffer $(0.25 \mathrm{X}$ Tris borate/EDTA). The oligonucleotide used for the gel shift analysis was $\mathrm{NF}-\kappa \mathrm{B}$ 5'-AGTTGAGGGGACTTTCCCAGGC-3'. The sequence motifs within the oligonucleotides are underlined.

Immunofluorescence. Cells grown on coverslips were fixed in $3.7 \%$ paraformaldehyde/PBS for $30 \mathrm{~min}$ and permeabilized with $0.1 \%$ Triton $\mathrm{X}-100$ for $10 \mathrm{~min}$. Cells were incubated with fluorescein isothiocyanate-phalloidin (FITC-phalloidin) for $60 \mathrm{~min}$ at room temperature to localize F-actin filaments. Single plain images of the cells were obtained by confocal laser scanning microscopy (Leica TCS SP5, Mannheim, Germany).

Statistical analysis. Data are expressed as the means \pm SD. Comparisons between more than two conditions were performed with the one-way ANOVA test followed by the LSD and SNK test (western blot analysis and real-time PCR data). $\mathrm{P}<0.05$ was considered to indicate statistically significant differences. All tests were performed with SPSS version 17.0.

\section{Results}

Long-term low-dose ADMA increases TGF- $\beta$ production in HUVECs. HUVECs were cultured until the ninth passage and incubated in the presence of different low-dose concentrations of ADMA (5 and $10 \mu \mathrm{mol} / \mathrm{l})$, which were replaced every $48 \mathrm{~h}$ starting from the fourth passage. Both protein (Fig. 1A, C and E) and mRNA (Fig. 1B, D and F) levels of TGF- $\beta$ were determined at the fifth, seventh, and ninth passage. In each passage (P5, P7, P9), both concentrations of ADMA (5 and $10 \mu \mathrm{mol} / \mathrm{l}$ ) significantly increased TGF- $\beta$ production compared with untreated cells. More obvious effects were observed in the higher concentration.

Long-term low-dose ADMA increases TGF- $\beta$ production in HUVECs in a time-dependent manner. To investigate the correlation between TGF- $\beta$ expression and ADMA, HUVECs were cultured until the ninth passage and incubated in the presence of low-dose of ADMA (5 and $10 \mu \mathrm{mol} / \mathrm{l}$ ), which was replaced every $48 \mathrm{~h}$ starting from passage four. Both protein (Fig. 2A, C and E) and mRNA (Fig. 2B, D and F) levels of TGF- $\beta$ were determined at the third, fifth, seventh, and ninth 

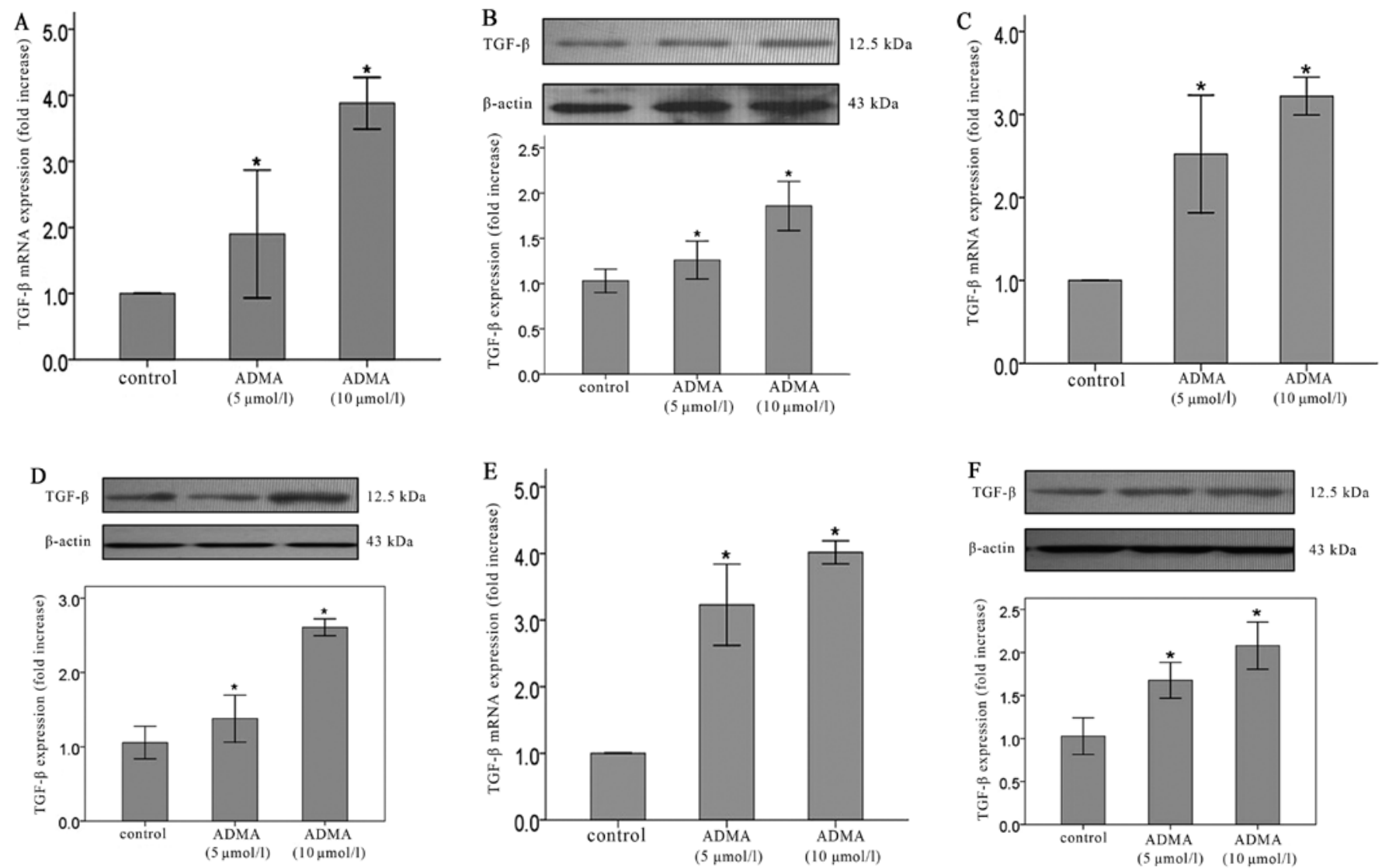

Figure 1. Effects of different levels of ADMA on TGF- $\beta$ expression in HUVECs. (A-E) HUVECs were incubated with ADMA (5 and $10 \mu \mathrm{mol} / \mathrm{l})$ starting from the fourth passage and replaced every $48 \mathrm{~h}$. (A) mRNA level of TGF- $\beta$ expression was measured with western blot analysis in passage five. (B) Protein level of TGF- $\beta$ expression was measured with real-time PCR in passage five. (C) mRNA level of TGF- $\beta$ expression was measured with western blot analysis in passage seven. (D) Protein level of TGF- $\beta$ expression was measured with real-time PCR in passage seven. (E) mRNA level of TGF- $\beta$ expression was measured with western blot analysis in passage nine. (F) Protein level of TGF- $\beta$ expression was measured with real-time PCR in passage nine. Results are presented as the means \pm SD from three independent experiments. ${ }^{*} \mathrm{P}<0.05$, compared with control cells.

passage. The results showed that both the mRNA and protein levels of TGF- $\beta$ were increased in a time-dependent manner (Fig. 2C-F) in the cells exposed to low-dose ADMA. The time-dependent manner was absent in control cells without ADMA stimulation (Fig. 2A and B).

Since TGF- $\beta$, a pleiotropic cytokine, is also present in control cells, and is involved in the effects of cell apoptosis, the following formula was used for correction:

Relative TGF- $\beta$ expression $=$ TGF- $\beta$ expression in ADMAstimulated (5 and $10 \mu \mathrm{mol} / \mathrm{l}$ ) cells/TGF- $\beta$ expression in control cells.

In Fig. 3 , the changes in TGF- $\beta$ production in endothelial cells are shown as a function of passage number. Treatment of cultured endothelial cells with ADMA (5 and $10 \mu \mathrm{mol} / \mathrm{l}$ ) significantly increased TGF- $\beta$ production compared with untreated cells in a time-dependent manner.

Reorganization of actin filaments inhibits ADMA-induced stress fiber formation and TGF- $\beta$ expression in HRGECs. To address the role of actin cytoskeleton in the mechanism of ADMA-induced NF- $\kappa \mathrm{B}$ activation in HRGECs, we firstly evaluated the effect of reorganizing actin filaments on NF- $\kappa \mathrm{B}$ dependent reporter gene activity. We used the four types of agents which can prevent the formation of actin stress fibers induced by ADMA. Analysis by immunofluorescence microscopy of HRGECs showed that the cells of the control group were polygonal in shape and F-actin was found mostly in the cortical regions comprising the cortical actin bands (Fig. 4A), which rearranged into stress fibers after treatment with ADMA (Fig. 4B). Pre-treatment with $5 \mu \mathrm{M}$ Cyto D, the prototypic actin depolymerizing drug, induced obvious destabilization of the actin filaments and then prevented the formation of stress fibers induced by ADMA (Fig. 4E). Similar effects were observed with the presence of SB 203580, the p38 MAPK inhibitor (Fig. 4C), apocynin, the NADPH oxidase inhibitor (Fig. 4D), and Jas, the prototypic actin stabilizing drug (Fig. 4F).

Since $\mathrm{NF}-\kappa \mathrm{B}$ is an essential regulator of TGF- $\beta$ transcription, we determined if the effects of reorganization of the actin filaments on $\mathrm{NF}-\kappa \mathrm{B}$ activity are reproduced on ADMA-induced TGF- $\beta$ expression in HRGECs. Western blot analysis showed that HRGECs exposed to ADMA (100 $\mu \mathrm{mol} / \mathrm{l})$ expressed much higher levels of TGF- $\beta$ than control cells and the increased TGF- $\beta$ protein was significantly inhibited in cells pre-treated with Cyto D $(5 \mu \mathrm{mol} / \mathrm{l})$ or Jas $(1 \mu \mathrm{mol} / \mathrm{l})$ for $30 \mathrm{~min}$ (Fig. 5A). However, the drugs per se have no significant effect on TGF- $\beta$ expression. The similar inhibition of ADMA-induced TGF- $\beta$ expression was also observed from the pre-treatment of p38 MAPK inhibitor and NADPH oxidase inhibitor (Fig. 5B). 

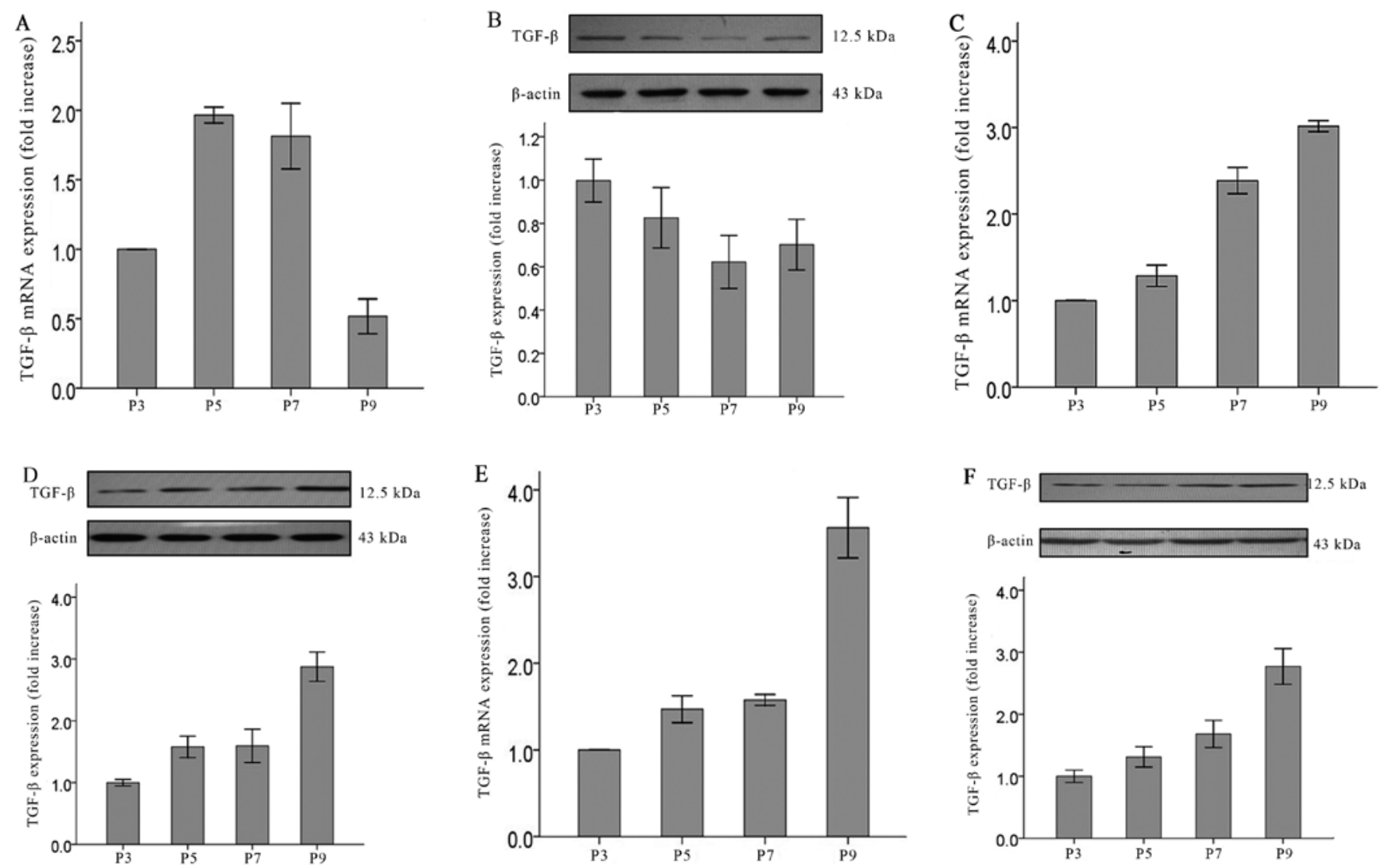

Figure 2. Effects of different concentrations of ADMA on TGF- $\beta$ expression in HUVECs. (A-E) HUVECs were cultured until the ninth passage and incubated in the presence of low-dose concentrations of ADMA ( 5 and $10 \mu \mathrm{mol} / 1)$, which were replaced every $48 \mathrm{~h}$ starting from passage four. The cells at passage three without ADMA stimulation were used as control cells. (A) mRNA level of TGF- $\beta$ expression was measured with western blot analysis in control cells with different passages. (B) Protein level of TGF- $\beta$ expression was measured with real-time PCR in control cells with different passages. (C) mRNA level of TGF- $\beta$ expression was measured with western blot analysis in $5 \mu \mathrm{mol} / 1$ ADMA-stimulated cells with different passages. (D) Protein level of TGF- $\beta$ expression was measured with realtime PCR in $5 \mu \mathrm{mol} / 1$ ADMA-stimulated cells with different passages. (E) mRNA level of TGF- $\beta$ expression was measured with western blot analysis in $10 \mu \mathrm{mol} / 1$ ADMA-stimulated cells with different passages. (F) Protein level of TGF- $\beta$ expression was measured with real-time PCR in $10 \mu$ mol/1 ADMA-stimulated cells with different passages. Results are presented as the means \pm SD from three independent experiments. ${ }^{*} \mathrm{P}<0.05$, compared with control cells.
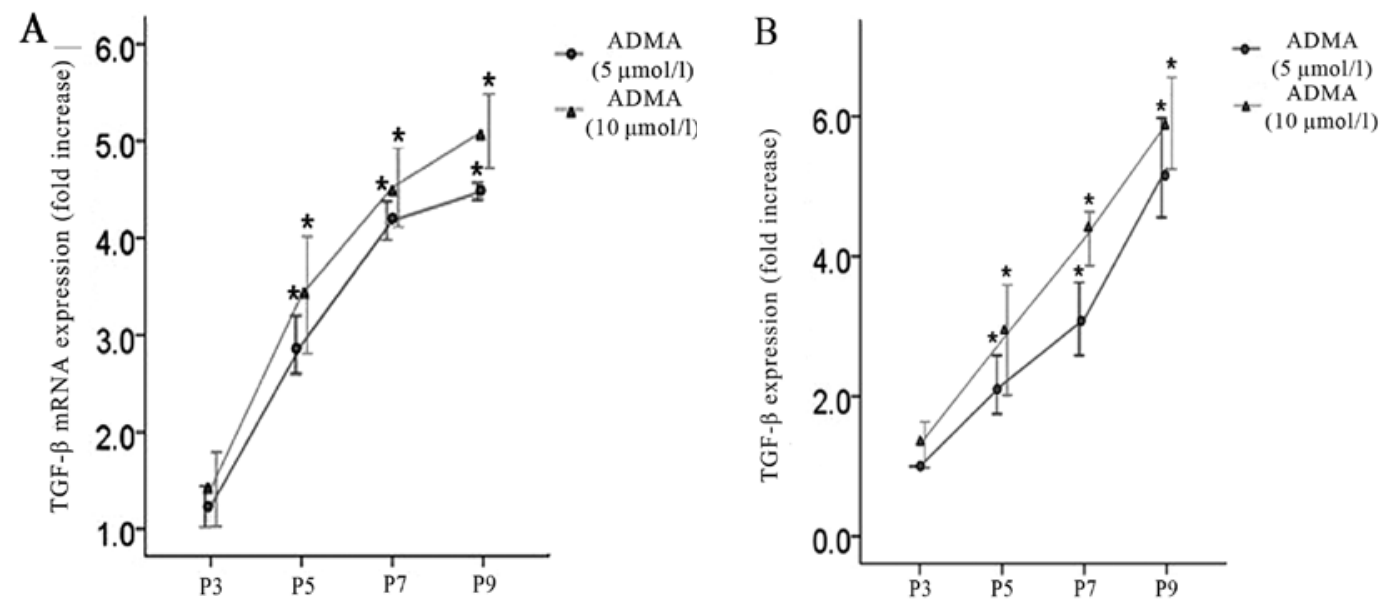

Figure 3. Effects of long-term low-dose ADMA on TGF- $\beta$ expression in HUVECs. HUVECs were cultured until the ninth passage and incubated in the presence of low-dose concentrations of ADMA ( 5 and $10 \mu \mathrm{mol} / \mathrm{l}$ ), which were replaced every $48 \mathrm{~h}$ starting from passage four. The cells at passage three without ADMA stimulation were used as control cells. (A) mRNA level of TGF- $\beta$ expression in ADMA-treated cells was measured with western blot analysis using the corrected formation. (B) Protein level of TGF- $\beta$ expression in ADMA-treated cells was measured with real-time PCR using the corrected formation. Results are presented as the means \pm SD from three independent experiments. " $\mathrm{P}<0.05$, compared with control cells.

Reorganization of actin filaments prevents ADMA-induced $N F-\kappa B D N A$ binding activity. The results of EMSA revealed that the control group showed a faint shift, while the cells exposed to ADMA $(100 \mu \mathrm{mol} / \mathrm{l})$ produced a strong shift. In subsequent experiments, it was found that both Cyto D and Jas reduced the DNA binding of $N F-\kappa B$ in response to ADMA 

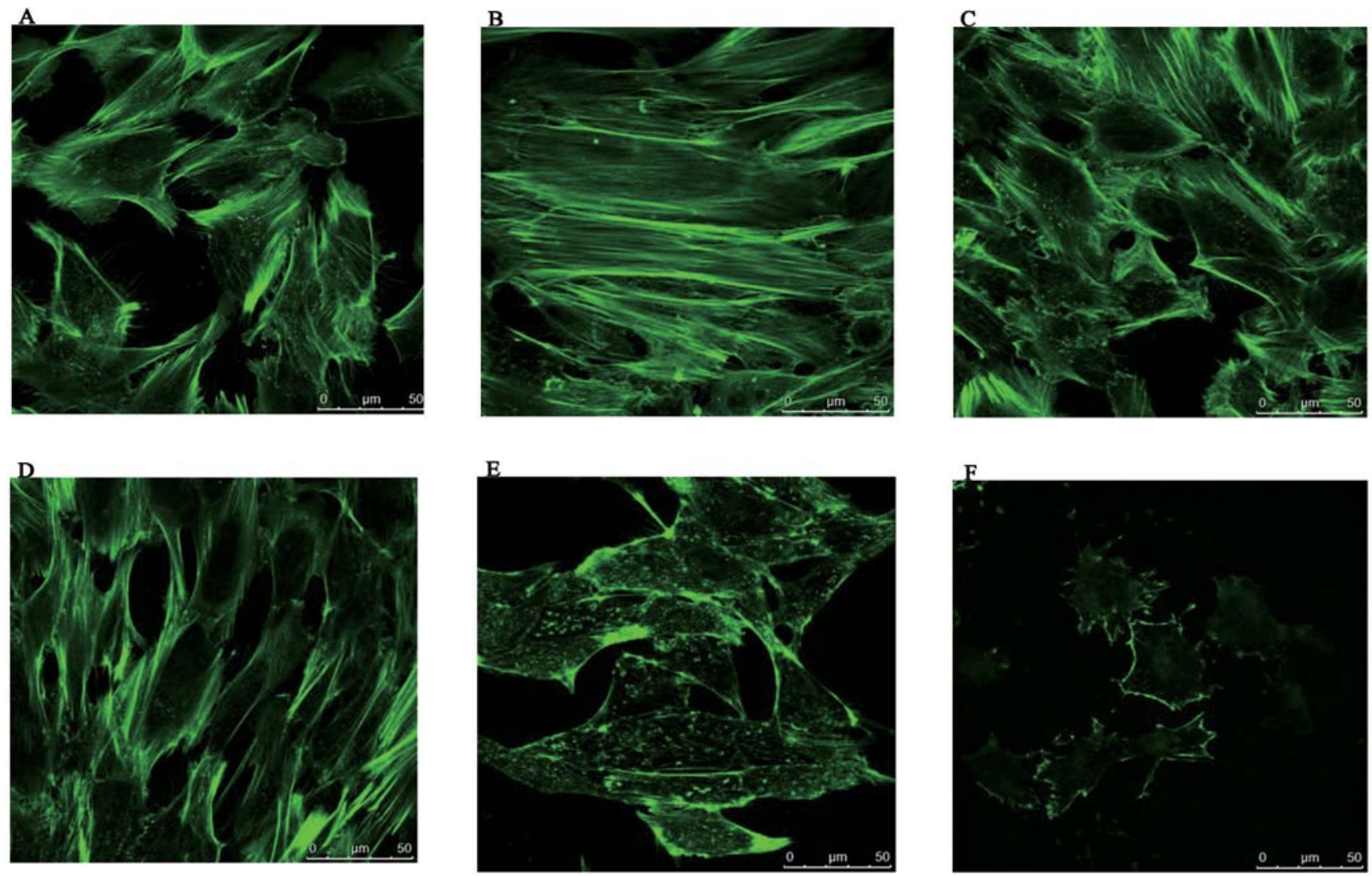

Figure 4. Effects of ADMA and interferents on actin stress fiber formation in HRGECs. HRGECs were stained with FITC-phalloidin to visualize F-actin by immunofluorescence microscopy after the treatment. (A) Before the treatment. (B) After the treatment of $100 \mu \mathrm{M}$ ADMA for $24 \mathrm{~h}$. (C-F) Pre-treatment of interferent [(C) $10 \mu \mathrm{M}$ SB 203580, (D) $100 \mu \mathrm{M}$ apocynin, (E) $5 \mu \mathrm{M}$ Cyto D, (F) $1 \mu \mathrm{M} \mathrm{Jas}$ ] for $30 \mathrm{~min}$ prior to challenge with $100 \mu \mathrm{M}$ ADMA for $24 \mathrm{~h}$.

A
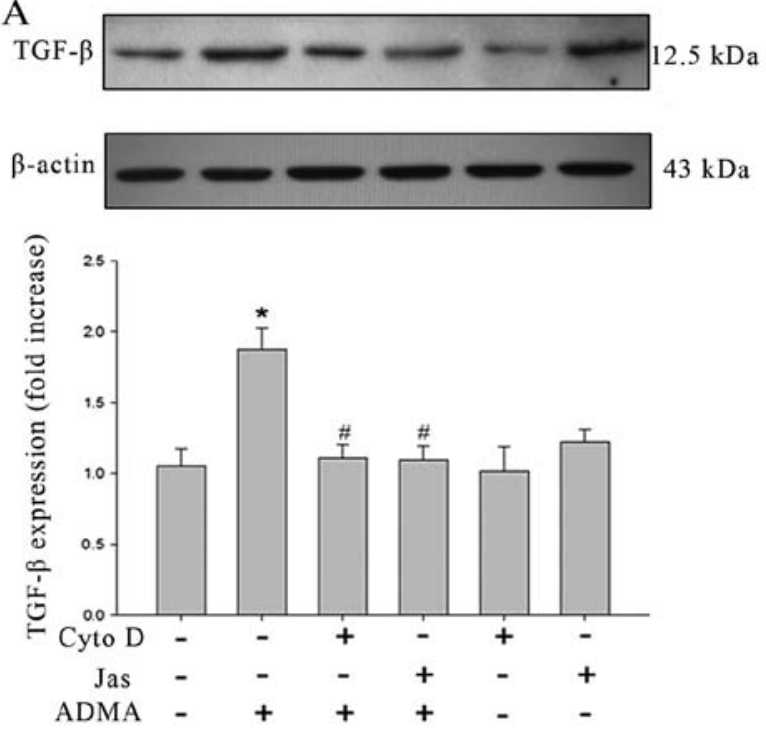

B
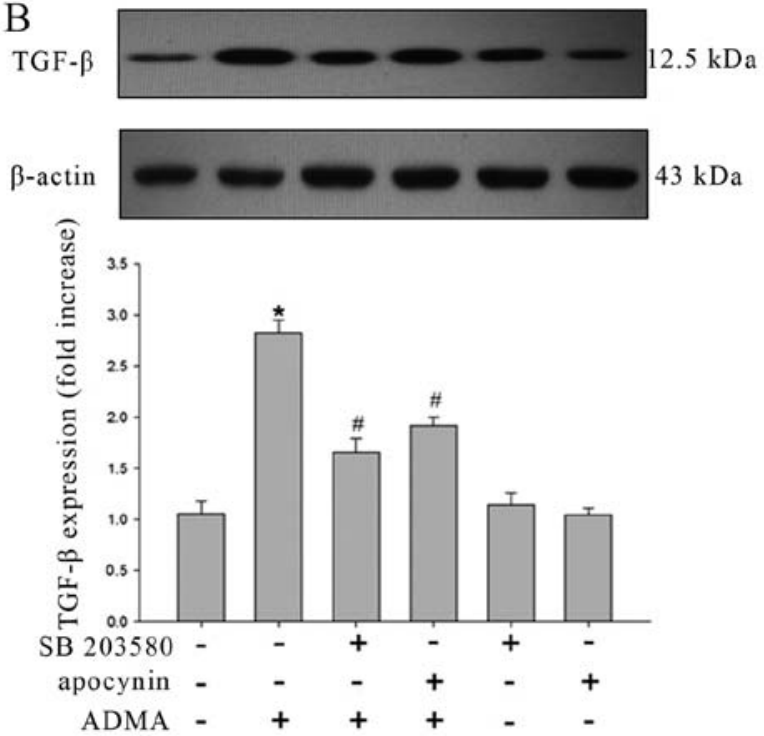

Figure 5. (A) Effects of stabilization and destabilization of the actin filaments on ADMA-induced TGF- $\beta$ expression; (B) effects of p38 MAPK inhibitor and NADPH oxidase inhibitor of the actin filaments on ADMA-induced TGF- $\beta$ expression. Data are presented as the means \pm SD from three independent experiments. Different from controls (" $\mathrm{P}<0.05)$; different from ADMA-stimulated cells $\left({ }^{*} \mathrm{P}<0.05\right)$.

challenge (Fig. 6A). The similar inhibition of ADMA-induced $\mathrm{NK}-\kappa \mathrm{B}$ nuclear translocation was also observed from the cells pretreated by p38 MAPK inhibitor and NADPH oxidase inhibitor (Fig. 6B).

\section{Discussion}

The main purpose of this study was to demonstrate that ADMA, the endogenous NOS inhibitor, can induce TGF- $\beta$ 
A
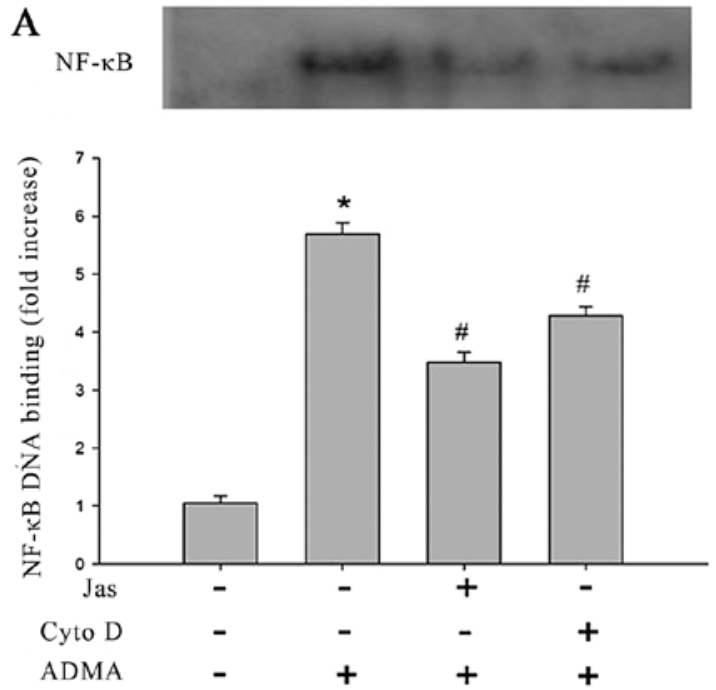
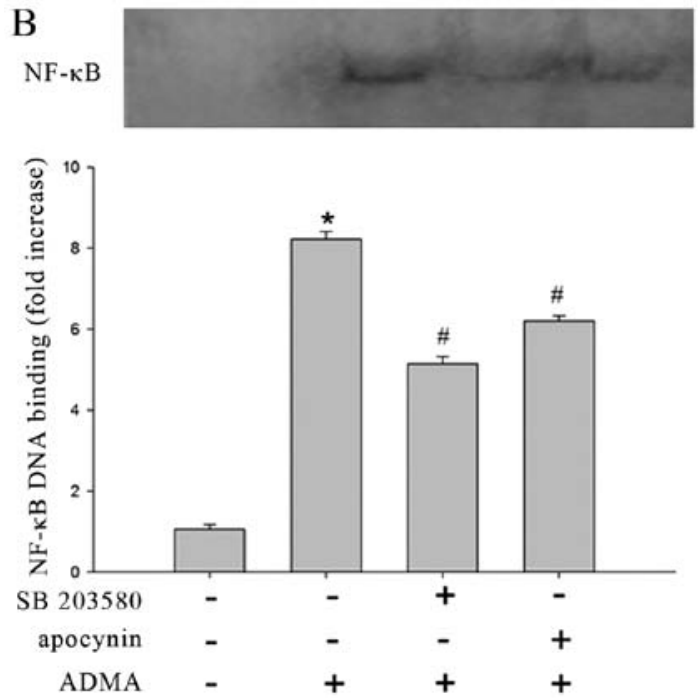

Figure 6. (A) Effects of stabilization and destabilization of the actin filaments on ADMA-induced DNA binding of NF- $\kappa$ B; (B) effects of p38 MAPK inhibitor and NADPH oxidase inhibitor on ADMA-induced DNA binding of NF- $\kappa$ B. Data are presented as the means \pm SD from three independent experiments. Different from controls $\left({ }^{*} \mathrm{P}<0.05\right)$; different from ADMA-stimulated cells $\left({ }^{\#} \mathrm{P}<0.05\right)$.

expression in endothelial cells, and that cytoskeleton organization may be involved in modulating ADMA-induced NF- $\mathrm{B}$ activation and the ensuing TGF- $\beta$ expression in HRGECs.

$\mathrm{NF}-\kappa \mathrm{B}$ is a ubiquitously expressed family of transcription factors controlling varied biological effects ranging from inflammatory, oxidative stress, and stress-induced responses to cell fate decisions such as proliferation, differentiation, tumorigenesis, and apoptosis (18-20). Fazal et al (9) revealed the existence of actin cytoskeleton-dependent and -independent pathways that may be involved in a stimulus-specific manner to facilitate NF- $\kappa \mathrm{B}$ nuclear import and thereby ICAM-1 expression in endothelial cells. We have already confirmed that stabilization and destabilization of the actin filaments prevented ADMA-induced NF- $\kappa \mathrm{B}$ activation and the ensuing cytokine production in HUVECs (8). However, it was confirmed that the actin organization responses to ADMA challenge and the subsequent NF- $\kappa \mathrm{B}$ activation are cell type specific (21), and, to date, how cytoskeleton responds to ADMA stimulation and the role of cytoskeleton reorganization in ADMA-induced NF- $\mathrm{BB}$ activation in HRGECs has yet to be investigated. In the present study, we demonstrated that ADMA significantly enhanced the stress fiber formation and active DNA binding of $\mathrm{NF}-\kappa \mathrm{B}$ in HRGECs, and such effects were inhibited by pre-treatment with actin depolymerizing or stabilizing drug.

Previous studies have demonstrated that the p38 MAPK and NADPH pathways may be involved in the cytoskeleton formation. Accumulating evidence suggests that ROS are important regulators of the actin cytoskeletal dynamics and cellular motility, and an important source of ROS within endothelial cells is the non-phagocytic NADPH oxidase (22). It has been demonstrated that NADPH oxidase activation and the ensuing ROS production associated with actin or with the F-actin binding protein moesin (23-25), dramatically increasing the speed of actin polymerization. Furthermore, phosphorylation of Hsp27, the downstream effector of $\mathrm{p} 38$ (26), leads to dissociation of multimers and promotes actin polymerization (27). Inhibiting p38 can inhibit stress fiber formation in adherent cells and lead to a decrease in cell permeability (28-30). We have already confirmed that ADMA increases endothelial permeability, which may involve the p38 MAPK and NADPH oxidase pathway in HUVECs (10). In the experiments presented here, it has been demonstrated that the inhibition of the p38 MAPK pathway and NADPH oxidase activation can inhibit the ADMA-induced NK- $\kappa \mathrm{B}$ activation via decreasing cytoskeleton reorganization in HRGECs, suggesting the cytoskeleton is involved in modulating the $\mathrm{NF}-\kappa \mathrm{B}$ nuclear transcription.

Findings of this study show that the inhibition of NOS by ADMA increased the expression of TGF- $\beta$ in HUVECs after the repeated addition of ADMA. ADMA is considered an independent mortality and cardiovascular risk factor in CKD patients (11-13), possibly contributing to the progression of CKD (14-16). Evidence has implicated TGF- $\beta$ as a major causative agent in the pathogenesis of tubulointerstitial fibrosis in CKD $(31,32)$. Recently, blockade of NOS or NO deficiency was reported to promote cardiac or renal fibrosis, respectively, via induction of TGF- $\beta(33,34)$, thus suggesting the pathological role for the ADMA-elicited NO reduction in fibrosis in various aggressive disorders. Mihout et al (17) demonstrated that high levels of ADMA induced renal TGF- $\beta$ production associated with increased renal oxidative stress in uninephrectomized mice, dimethylarginine dimethylaminohydrolase (DDAH) ameliorated the renal dysfunction by reducing ADMA accumulation (14), while the precise molecular mechanisms were not explicit. It is known that ADMA increases TGF- $\beta$ expression via the $\mathrm{NO} / \mathrm{NF}-\kappa \mathrm{B}$ pathway in hepatic stellate cells, while there is no report on ADMA-induced NF- $\kappa \mathrm{B}$ activity and the ensuing TGF- $\beta$ expression in endothelial cells. Our study demonstrated that ADMA-induced TGF- $\beta$ expression is associated with NF- $\kappa$ B activity, but whether other pathways are also involved in the effect remains to be confirmed in future studies.

TGF- $\beta$, a pleiotropic cytokine, regulates cell proliferation, differentiation, and apoptosis, and plays a key role in develop- 
ment and tissue homeostasis. Hence, in untreated cells, TGF- $\beta$ also expressed along with the growth of cells. The results presented here show that in the control cells without ADMA stimulation, TGF- $\beta$ expression was not time-dependent. We analyzed the relative TGF- $\beta$ expression using the corrected formula mentioned previously to exclude the influencing factor with the normal cell apoptosis and other cell homeostasis. The experiment demonstrated that long-term low-dose ADMA increased TGF- $\beta$ production in both mRNA and protein levels in HUVECs in a time-dependent manner.

Moreover, in this investigation, more obvious TGF- $\beta$ production was observed in the higher ADMA concentration. Hence we can assume that ADMA accumulated in the progression of CKD, associated with the higher blood concentration, induced the TGF- $\beta$ production in endothelial cells along with the extension of stimulation time, which could cause the renal fibrosis.

The dose of ADMA used in previous in vitro studies was usually relatively high $(100 \mu \mathrm{mol} / \mathrm{l})$, however the blood level of ADMA is $1-10 \mu \mathrm{mol} / 1$ reported in patients with chronic renal disease. We demonstrated that long-term low-dose of ADMA induces TGF- $\beta$ expression in endothelial cells via NF- $\kappa \mathrm{B}$ activation and highlighted the cytoskeleton related pathways responsible.

To date, the technology of extracting HRGECs has not been improved significantly. In our experiment, the cells failed to grow at the fifth or sixth passage, hence the long-term stimulation can not be implemented in HRGECs and we used HUVECs to replace them. They have common endothelial cell characteristics and HUVECs have also been studied extensively in kidney research. Whether long-term low-dose ADMA challenge induces cytokine expression in HRGECs remains to be studied.

Furthermore, while there is emerging evidence that the reorganization of cytoskeleton in endothelial cells can be protectable for endothelial dysfunction, it remains to be determined whether it can protect the renal fibrosis in further in vivo studies.

In summary, the present study demonstrated that long-term low-dose ADMA induces TGF- $\beta$ expression in endothelial cells at both the gene and protein level, which may be involved in the development of renal fibrosis. Actin cytoskeleton may be involved in modulated ADMA-induced NF- $\mathrm{B}$ activation and the ensuing TGF- $\beta$ expression in HRGECs.

\section{Acknowledgements}

The present study was financially supported by the Beijing Municipal Science and Technology Commission Funds (D09050704310903), the Collaborative Project Funds on Fundamental and Clinical Research of Capital Medical University (10JL26) and the Specialized Research Fund for the Doctoral Program of Higher Education (SRFDP) (20101107120003).

\section{References}

1. Boger RH: Asymmetric dimethylarginine, an endogenous inhibitor of nitric oxide synthase, explains the 'L-arginine paradox' and acts as a novel cardiovascular risk factor. J Nutr 134 (Suppl 10): S2842-S2853, 2004.
2. Cooke JP: Does ADMA cause endothelial dysfunction. Arterioscler Thromb Vasc Biol 20: 2032-2037, 2000.

3. Boger RH: Asymmetric dimethylarginine (ADMA) and cardiovascular disease: insights from prospective clinical trials. Vasc Med 10 (Suppl 1): S19-S25, 2005.

4. Palm F, Onozato ML, Luo Z and Wilcox CS: Dimethylarginine dimethylaminohydrolase (DDAH): expression, regulation, and function in the cardiovascular and renal systems. Am J Physiol Heart Circ Physiol 293: H3227-H3245, 2007.

5. Teerlink T, Luo Z, Palm F and Wilcox CS: Cellular ADMA: regulation and action. Pharmacol Res 60: 448-460, 2009.

6. Scalera F, Borlak J, Beckmann B, et al: Endogenous nitric oxide synthesis inhibitor asymmetric dimethyl L-arginine accelerates endothelial cell senescence. Arterioscler Thromb Vasc Biol 24: 1816-1822, 2004.

7. Li JC, Chang L, Lu D, Jiang DJ and Tan DM: Effect of asymmetric dimethylarginine on the activation of hepatic stellate cells and its mechanism. Zhong Nan Da Xue Xue Bao Yi Xue Ban 32: 427-432, 2007 (In Chinese).

8. Guo WK, Zhang DL, Wang XX, Zhang Y, Zhang QD and Liu WH: Actin cytoskeleton modulates ADMA-induced NF-kappaB nuclear translocation and ICAM-1 expression in endothelial cells. Med Sci Monit 17: BR242-BR247, 2011.

9. Fazal F, Minhajuddin M, Bijli KM, McGrath JL and Rahman A: Evidence for actin cytoskeleton-dependent and -independent pathways for RelA/p65 nuclear translocation in endothelial cells. J Biol Chem 282: 3940-3950, 2007.

10. Wang LY, Zhang DL, Zheng JF, Zhang Y, Zhang QD and Li WH: Apelin-13 passes through the ADMA-damaged endothelial barrier and acts on vascular smooth muscle cells. Peptides 32: 2436-2443, 2011.

11. Fliser D, Kronenberg F, Kielstein JT, et al: Asymmetric dimethylarginine and progression of chronic kidney disease: the mild to moderate kidney disease study. J Am Soc Nephrol 16: 2456-2461, 2005.

12. Zoccali C, Bode-Boger S, Mallamaci F, et al: Plasma concentration of asymmetrical dimethylarginine and mortality in patients with end-stage renal disease: a prospective study. Lancet 358: 2113-2117, 2001

13. Zoccali C: Traditional and emerging cardiovascular and renal risk factors: an epidemiologic perspective. Kidney Int 70: 26-33, 2006.

14. Matsumoto Y, Ueda S, Yamagishi S, et al: Dimethylarginine dimethylaminohydrolase prevents progression of renal dysfunction by inhibiting loss of peritubular capillaries and tubulointerstitial fibrosis in a rat model of chronic kidney disease. J Am Soc Nephrol 18: 1525-1533, 2007.

15. Wagner L, Riggleman A, Erdely A, Couser W and Baylis C: Reduced nitric oxide synthase activity in rats with chronic renal disease due to glomerulonephritis. Kidney Int 62: 532-536, 2002.

16. Ravani P, Tripepi G, Malberti F, Testa S, Mallamaci F and Zoccali C: Asymmetrical dimethylarginine predicts progression to dialysis and death in patients with chronic kidney disease: a competing risks modeling approach. J Am Soc Nephrol 16: 2449-2455, 2005.

17. Mihout F, Shweke N, Bige N, et al: Asymmetric dimethylarginine (ADMA) induces chronic kidney disease through a mechanism involving collagen and TGF-beta1 synthesis. J Pathol 223: 37-45, 2011.

18. Aggarwal BB: Nuclear factor-kappa B: the enemy within. Cancer Cell 6: 203-208, 2004

19. Hayden MS and Ghosh S: Signaling to NF-kappaB. Genes Dev 18: 2195-2224, 2004.

20. Karin M and Lin A: NF-kappa B at the crossroads of life and death. Nat Immunol 3: 221-227, 2002.

21. Wojciak-Stothard B, Torondel B, Tsang LY, et al: The ADMA/ DDAH pathway is a critical regulator of endothelial cell motility. J Cell Sci 120: 929-942, 2007.

22. Moldovan L, Mythreye K, Goldschmidt-Clermont PJ and Satterwhite LL: Reactive oxygen species in vascular endothelial cell motility. Roles of NAD(P)H oxidase and Racl. Cardiovasc Res 71: 236-246, 2006.

23. Li JM and Shah AM: Intracellular localization and preassembly of the NADPH oxidase complex in cultured endothelial cells. J Biol Chem 277: 19952-19960, 2002.

24. Tamura M, Kai T, Tsunawaki S, Lambeth JD and Kameda K: Direct interaction of actin with p47(phox) of neutrophil NADPH oxidase. Biochem Biophys Res Commun 276: 1186$1190,2000$. 
25. Wientjes FB, Reeves EP, Soskic V, Furthmayr H and Segal AW: The NADPH oxidase components p47(phox) and p40(phox) bind to moesin through their PX domain. Biochem Biophys Res Commun 289: 382-388, 2001.

26. Gerthoffer WT and Gunst SJ: Invited review: focal adhesion and small heat shock proteins in the regulation of actin remodeling and contractility in smooth muscle. J Appl Physiol 91: 963-972, 2001.

27. McMullen ME, Bryant PW, Glembotski CC, Vincent PA and Pumiglia KM: Activation of p38 has opposing effects on the proliferation and migration of endothelial cells. J Biol Chem 280: 20995-21003, 2005.

28. Lamalice L, Houle F, Jourdan G and Huot J: Phosphorylation of tyrosine 1214 on VEGFR2 is required for VEGF-induced activation of Cdc42 upstream of SAPK2/p38. Oncogene 23: 434-445, 2004.

29. Garcia JG, Wang $P$, Schaphorst KL, et al: Critical involvement of p38 MAP kinase in pertussis toxin-induced cytoskeletal reorganization and lung permeability. FASEB J 16: 1064-1076, 2002 .
30. Song C, Perides G, Wang D and Liu YF: beta-Amyloid peptide induces formation of actin stress fibers through p38 mitogenactivated protein kinase. J Neurochem 83: 828-836, 2002.

31. Okuda S, Languino LR, Ruoslahti E and Border WA: Elevated expression of transforming growth factor-beta and proteoglycan production in experimental glomerulonephritis. Possible role in expansion of the mesangial extracellular matrix. J Clin Invest 86: 453-462, 1990.

32. Tamaki K, Okuda S, Ando T, Iwamoto T, Nakayama M and Fujishima M: TGF-beta 1 in glomerulosclerosis and interstitial fibrosis of adriamycin nephropathy. Kidney Int 45: 525-536, 1994.

33. Boffa JJ, Lu Y, Placier S, Stefanski A, Dussaule JC and Chatziantoniou C: Regression of renal vascular and glomerular fibrosis: role of angiotensin II receptor antagonism and matrix metalloproteinases. J Am Soc Nephrol 14: 1132-1144, 2003.

34. Tomita H, Egashira K, Ohara Y, et al: Early induction of transforming growth factor-beta via angiotensin II type 1 receptors contributes to cardiac fibrosis induced by long-term blockade of nitric oxide synthesis in rats. Hypertension 32: 273-279, 1998. 